\title{
Is the Frequency in Somatosensory Electrical Stimulation the Key Parameter in Modulating the Corticospinal Excitability of Healthy Volunteers and Stroke Patients with Spasticity?
}

\author{
Marco Antonio Cavalcanti Garcia, ${ }^{1,2,3}$ João Marcos Yamasaki Catunda, ${ }^{1}$ Marcio Nogueira de \\ Souza, ${ }^{1}$ Ana Paula Fontana, ${ }^{4}$ Sandro Sperandei, ${ }^{5}$ and Claudia D. Vargas ${ }^{2}$ \\ ${ }^{1}$ Laboratório de Instrumentação Biomédica, Programa de Engenharia Biomédica, COPPE, Universidade Federal do Rio de Janeiro, \\ Avenida Horácio Macedo 2030, CT, Bloco H, Sala 327, Cidade Universitária, 21941-914 Ilha do Fundão, RJ, Brazil \\ ${ }^{2}$ Laboratório de Neurobiologia II, Instituto de Biofísica Carlos Chagas Filho, Universidade Federal do Rio de Janeiro, \\ Avenida Carlos Chagas Filho 373, CCS, Bloco G, Sala G1-019, Cidade Universitária, 21941-902 Ilha do Fundão, RJ, Brazil \\ ${ }^{3}$ Departamento de Biociências da Atividade Física, Escola de Educação Física e Desportos, Universidade Federal do Rio de Janeiro, \\ Avenida Carlos Chagas Filho 540, Cidade Universitária, 21941-599 Ilha do Fundão, RJ, Brazil \\ ${ }^{4}$ Departamento de Fisioterapia, Faculdade de Medicina, Universidade Federal do Rio de Janeiro, Avenida Carlos Chagas Filho 373 , \\ CCS, Bloco K, Sala K2-49, Cidade Universitária, 21941-902 Ilha do Fundão, RJ, Brazil \\ ${ }^{5}$ Instituto de Comunicação e Informação Científica e Tecnológica em Saúde (ICICT), Fundação Oswaldo Cruz (FIOCRUZ), \\ Avenida Brasil 4365, 21040-900 Manguinhos, RJ, Brazil \\ Correspondence should be addressed to Marco Antonio Cavalcanti Garcia; garcia@eefd.ufrj.br
}

Received 9 July 2015; Accepted 23 November 2015

Academic Editor: Ela Plow

Copyright (C) 2016 Marco Antonio Cavalcanti Garcia et al. This is an open access article distributed under the Creative Commons Attribution License, which permits unrestricted use, distribution, and reproduction in any medium, provided the original work is properly cited.

\begin{abstract}
Somatosensory electrical stimulation (SES) has been proposed as an approach to treat patients with sensory-motor impairment such as spasticity. However, there is still no consensus regarding which would be the adequate SES parameters to treat those deficits. Therefore, the aim of this study was to evaluate the effects of applying SES over the forearm muscles at four different frequencies of stimulation $(3,30,150$, and $300 \mathrm{~Hz})$ and in two intervals of time $\left(5^{\prime}\right.$ and $\left.30^{\prime}\right)$ by means of transcranial magnetic stimulation and Hoffmann's reflex (H-reflex) in healthy volunteers (Experiments I and II). A group of stroke patients (Experiment III) was also preliminary evaluated to ascertain SES effects at a low frequency $(3 \mathrm{~Hz})$ applied for $30^{\prime}$ over the forearm spastic flexors muscles by measuring the wrist joint passive torque. Motor evoked potentials and the H-reflex were collected from different forearm and hand muscles immediately before and after SES and up to $5^{\prime}$ (Experiment I) and 10' (Experiments I and II) later. None of the investigated frequencies of SES was able to operate as a key in switching modulatory effects in the central nervous system of healthy volunteers and stroke patients with spasticity.
\end{abstract}

\section{Introduction}

On the recent years, an approach known as somatosensory electrical stimulation (SES), which consists in applying peripheral electrical stimulation below or at the motor threshold (MT) level [1-3], has been employed to treat patients with sensory-motor impairments such as spasticity [4-8]. Although there are encouraging clinical results observed in stroke $[3,9]$ and spinal cord lesioned [10,
11] patients, several methodological aspects of using SES therapeutically remain unresolved [12]. Chipchase et al. [13] and Veldman et al. [14] performed systematic reviews of SES parameters upon the primary motor cortex (M1) and suggest that there is insufficient evidence to determine their effects. Additionally, there also seems to be a lack of consensus regarding the effects of SES over spinal circuits mainly due to methodological constraints, which are described in more details elsewhere [15]. 
TABLE 1: Main characteristics of the stroke patients.

\begin{tabular}{|c|c|c|c|c|c|c|c|}
\hline Patient & Age & Sex & $\begin{array}{l}\text { Months } \\
\text { after stroke }\end{array}$ & $\begin{array}{c}\text { Prestroke } \\
\text { hand dominant } \\
\text { hemisphere }\end{array}$ & Lesioned hemisphere & Lesion type & $\begin{array}{c}\text { Modified } \\
\text { Ashworth scale }\end{array}$ \\
\hline $\mathrm{P} 1$ & 59 & $\mathrm{M}$ & 37 & Left & Left & Ischemic & 2.0 \\
\hline P2 & 69 & M & 18 & Left & Left & Ischemic & 1.0 \\
\hline P3 & 45 & M & 48 & Left & Left & Hemorrhagic & 2.0 \\
\hline $\mathrm{P} 4$ & 63 & $\mathrm{~F}$ & 24 & Left & Left & Ischemic & $1.0+$ \\
\hline P5 & 70 & M & 51 & Left & Left & Hemorrhagic & 2.0 \\
\hline
\end{tabular}

Among SES underlying mechanisms, Ward [16] proposed that an increase in the frequency of stimulation upon the stimulated nerve would allow the ionic current to flow more deeply, leading to the recruitment of a larger pool of somatosensory receptors from different tissues adjacent to the SES stimulation site. Thus, distinct effects upon excitability in M1 and/or spinal circuitries would be expected depending on the average output of recruited sensory fibers. However, to our knowledge, no previous studies have compared the effects of more than two SES frequencies upon corticospinal and spinal excitability.

Therefore, the aim of this study was to evaluate by means of transcranial magnetic stimulation (TMS) and Hoffmann's reflex (H-reflex) in normal volunteers the effect of applying SES over the hand and forearm muscles at four different stimulation frequencies, conducted in two experiments. Moreover, a group of stroke patients was also preliminary evaluated to ascertain SES effects at a low frequency over the forearm spastic flexors muscles on the wrist joint passive torque.

\section{Materials and Methods}

2.1. Subjects. The first two experiments were performed with two groups of right-handed volunteers without neurological disorders. The first was composed of fourteen volunteers (seven males and seven females; age: 19.0-39.0 years; height: 1.54-1.92 m; body weight: 53.3-97.0 kg; Edinburgh Handedness Inventory [17]: $+30.0-+90.0)$ and the second comprised six volunteers (five males and one female; age: $20.0-37.0$ years; height: 1.54-1.92 m; body weight: 56.0-97.0 kg; Edinburgh Handedness Inventory [17]: $+40.0-+95.0)$. The criteria of inclusion and exclusion were based on Rossi et al. [18]. The first and second groups were subjected to $5^{\prime}$ and $30^{\prime}$ SES protocols, respectively, hereafter called Experiments I and II. Both application times were arbitrarily defined.

A third group composed of five chronic stroke patients (one female and four males; age: 45-70 years; height: 1.56$1.70 \mathrm{~m}$; body weight: $61.0-89.0 \mathrm{~kg}$ ) with spasticity, all righthanded (Edinburgh Handedness Inventory [17]: before stroke $[+86.67-+100.0]$; after stroke $[-100.0-+23.33])$, was also recruited for a pilot study concerning SES effects on spastic muscles (Experiment III). Among the adopted criteria of inclusion [18], the main one was to present spasticity on the right forearm limiting wrist movements with a maximum score of "2" ("More marked increase in muscle tone through most of the ranges of motion (ROM), but affected part(s) easily moved") based on the modified Ashworth scale [19]. Furthermore, cognition and skin sensitivity should be normal, which were evaluated by means of the Mini Mental State Examination [20] and Pain and Light Touch Sensation tests [21], respectively. All the stroke patients were independently evaluated by two experienced physical therapists. Individual characteristics of all stroke patients are summarized in Table 1.

The entire experimental protocols were submitted to the local ethical committee (process number: 082/08) and were conducted after each volunteer gave informed consent.

2.2. Experimental Designs. The first and the second groups (Experiments I and II) were subjected to four different frequencies of SES: 3, 30, 150, and $300 \mathrm{~Hz}$. The frequencies were chosen based on previous reports in which they resulted in motor control improvement and/or neuromodulation [2, 22$24]$ by using SES and other therapeutic modalities of electrical stimulation. The frequencies of stimulation were applied in a random manner in both experiments. In Experiment I, the effects of the four frequencies of SES upon corticospinal and spinal excitability were evaluated in the same experimental session. Each frequency of SES was applied for $5^{\prime}$ and was followed by a rest interval of $10^{\prime}$. Motor evoked potentials (MEPs) and H-reflex were collected immediately before (baseline) and after $\left(0^{\prime}\right)$ SES application and then $5^{\prime}$ later $\left(5^{\prime}\right)$. In contrast, in Experiment II, the volunteers were subjected to $30^{\prime}$ of SES for each frequency and the protocol was conducted on four different days separated by a minimum interval of 72 hours. Similarly to Experiment I, MEPs and H-reflex were collected immediately before (baseline) and after $\left(0^{\prime}\right)$ SES application and then $5^{\prime}\left(5^{\prime}\right)$ and $10^{\prime}\left(10^{\prime}\right)$ later. Each single experimental session lasted for approximately $4 \mathrm{~h}$.

In Experiment III, the stroke patients were submitted to SES therapy only at $3 \mathrm{~Hz}$ that was also applied for $30^{\prime}$ in one single session, similarly to Experiment II. We justify such decision due to the time consumption $(\sim 4 \mathrm{~h})$ of Experiments I and II and because previous authors [14] report interesting M1 modulatory effects when SES was applied below $10 \mathrm{~Hz}$. Additionally, the passive mechanical resistance of the right wrist joint in the extension movement was evaluated by means of an isokinetic system [25] only before (baseline) and immediately after $\left(0^{\prime}\right)$ SES therapy. 


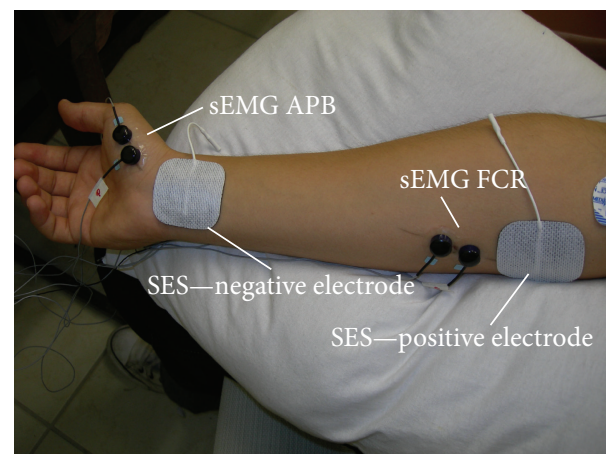

FIGURE 1: Surface electrode placement for SES. The positive electrode was placed near the elbow joint while the negative electrode was placed near the wrist joint. Surface electromyographic electrodes (in black) can be observed over the flexor carpi radialis (FCR) and abductor pollicis brevis (APB) muscle bellies.

2.3. SES Application. The SES pulse was a constant amplitude current waveform (an unbalanced asymmetrical biphasic pulse) with duration of $500 \mu$ s $[26,27]$. SES was delivered using a custom electrical stimulator (FES-PEB) built by Velloso and Souza [27]. Pulse intensity was set below the MT and was determined based on the volunteers' reports of a tingling sensation in the stimulated area (forearm flexor muscles) without any pain or visible movement of the wrist and fingers. Surface self-adhesive electrodes $(5 \times 5 \mathrm{~cm}$; model: CF5050, Axelgaard Manufacturing Co., Ltd., Denmark) were used for SES. SES intensities were set between 2-7 mA (Experiment I), 3-8 mA (Experiment II), and 3-5 mA (Experiment III). The surface electrodes were positioned over the right forearm, between the wrist (negative electrode) and the elbow (positive electrode) joints, parallel to the FCR muscle in the longitudinal direction (Figure 1).

Because it has been suggested that forearm rotation around its longitudinal axis may modulate spinal reflexes [28], the volunteers remained seated in a comfortable chair with the right forearm maintained in a prone position throughout the experiments.

2.4. TMS and H-Reflex Data Acquisition. A BIOPAC system (model: MP150; A/D converter: 16 bits; dynamic range: $\pm 10 \mathrm{~V}$; sampling frequency: $15 \mathrm{kHz}$; band pass filter: 4 th order and 100-5000 Hz; gain: 2000; BIOPAC Systems, Inc., USA) was used to collect the MEPs and H-reflex. Surface BIOPAC reusable electrodes $(\mathrm{Ag} / \mathrm{AgCl}$; diameter: $8 \mathrm{~mm})$ were placed following SENIAM recommendations [29] over the following muscle bellies: the flexor (FCR) and extensor (ECR) carpi radialis and abductor pollicis brevis (APB). The ECR and APB muscles were defined as controls in Experiments I and II. In Experiment III, we monitored one more muscle: the contralateral flexor carpi radialis (FCRc) from the nonaffected left forearm. Therefore, in this particular experiment, the FCRc, $\mathrm{ECR}$, and APB muscles were defined as controls.

A TMS butterfly coil (model: MagPro; MagVenture, Denmark) was positioned over the left M1 in the optimal scalp position (hot-spot) to elicit FCR motor responses in the contralateral hemibody. The hot-spot position was achieved using a cap with marks (grid: $1 \times 1 \mathrm{~cm}$ ) according to the international 10-20 system for electroencephalography. The FCR hot-spot was defined as the site in M1 in which a single magnetic pulse set at a minimum intensity produced a MEP response (amplitudes with more than $50 \mu \mathrm{V}$ in three out of six trials) in the relaxed muscle [30-32]. Then, the magnetic stimulus intensity was adjusted to $20 \%$ above the FCR resting MT.

As previously mentioned, MEPs were collected from all the muscles studied immediately before (baseline) and immediately after $\left(0^{\prime}\right)$ SES and up to $5^{\prime}$ (Experiment I) and $10^{\prime}$ (Experiments II and III) later after each session of SES and for each frequency. In each measurement, at least six (Experiment I) and ten (Experiments II and III) single TMS pulses were delivered with an interpulse interval of 5-10 s. The surface electromyographic (sEMG) data acquisition was triggered by a hardware pulse provided by the TMS system. Changes in spinal excitability were monitored through the evaluation of the mean value between the maximum and the minimum FCR H-reflex responses obtained by means of a curve of recruitment collected before the beginning of each SES session. To elicit the H-reflex from the FCR, a rectangular monophasic pulse of $800 \mu$ s was applied to a pair of surface electrodes, where one of the electrodes was placed over the median nerve (cathode: $\mathrm{Ag} / \mathrm{AgCl} ; 4 \mathrm{~mm}$ diameter), $\sim 4 \mathrm{~cm}$ above the elbow joint, and the other on the opposite limb (anode: $\mathrm{Ag} / \mathrm{AgCl} ; 47.5 \mathrm{~cm}^{2}$ ). The sEMG signal acquisition was started by a hardware pulse trigger provided by the stimulator. Once the electrical pulse was applied, a data window of $100 \mathrm{~ms}$ was collected and saved. The interpulse intervals varied between 5 and $10 \mathrm{~s}$ [33]. At least four sEMG signal data windows were obtained for further analysis due to the robustness of the collected H-reflex data. Regarding the FCR H-reflex, Experiment I provided suitable data only from seven volunteers (one man and six women; age: $19.0-31.0$ years; height: $1.55-1.73 \mathrm{~m}$; body mass: $53.3-$ $82.6 \mathrm{~kg}$; Edinburgh Handedness Inventory [17]: +60.0-+90.0) due to methodological constraints in recording it. Similarly, also due to methodological constraints, it was possible to collect the FCR H-reflex only from two stroke patients and, therefore, we decided not to present these data in this study.

Visual feedback of the sEMG signals was provided throughout all the experimental sessions to certify that all the volunteers were relaxed.

2.5. The Passive Wrist Torque Measurement. A custom-made device was built to evaluate the passive resistance of the wrist joint while being moved (Figure 2). It consisted of a stepper motor of $100 \mathrm{kgf} \cdot \mathrm{cm}$ static torque controlled by a micro-step driver to make small steps of $0.036^{\circ}$ that smoothed the movement. Attached to the stepper motor, a load cell allowed measuring the torque applied to the wrist. The data was recorded using a Spider 8 (HBM, Hottinger Baldwin Messtechnik) system with 16 bits, $4800 \mathrm{~Hz}$ sample rate, and an antialiasing filter set at $960 \mathrm{~Hz}$.

The root mean square (RMS) value of the force measured by a load cell was calculated and used as an estimate of the 


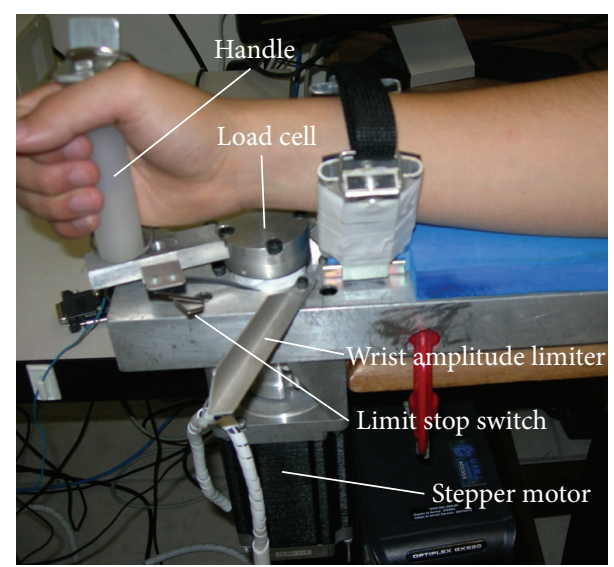

FIGURE 2: The isokinetic system that was built for measuring the passive mechanical resistance in the wrist joint. It provides the torque and angle data from cyclical wrist extensions with constant angular speed and range of movement.

torque $(\mathrm{gf} \cdot \mathrm{cm})$ during 5 cycles of 35 degrees of wrist extension set at an angular velocity of 10 degrees per second to avoid the stretch reflex [34].

2.6. Data and Statistical Analyses. Surface EMG signals collected from each muscle during Experiments I, II, and III and at each interval of time (baseline, $0^{\prime}$ and $5^{\prime}$ or $10^{\prime}$ ) were analyzed using an algorithm built in Matlab 6.5 (Mathworks, USA). This algorithm measured MEP and H-reflex peak-topeak (P-P) values, which represents corticospinal [35] and spinal [36] excitability. MEP and H-reflex median values were then obtained from each six (Experiment I) and ten (Experiments II and III) sEMG signal data windows were from the muscles previously mentioned for each group, resulting in one value for each interval of time, that is, before (baseline) and after $\left(0^{\prime}\right)$ SES application, as well as $5^{\prime}$ (Experiment I) and $10^{\prime}$ (Experiments II and III) later for each SES frequency and for each volunteer. The medians from $\mathrm{MEP}_{\mathrm{P}-\mathrm{P}}$ and $\mathrm{H}$-reflex $\mathrm{P}_{\mathrm{P}}$ values were then normalized by computing the ratio between the data for each interval of time $\left(0^{\prime}, 5^{\prime}\right.$, and $\left.10^{\prime}\right)$ and the corresponding baseline value achieved before SES multiplied by 100 [2, 37-39].

All normalized MEP data values were analyzed using a two-way repeated measures ANOVA (factors: interval of time $\times$ frequency) for each muscle individually. For the H-reflex data, a two-way repeated measures ANOVA (factors: interval of time $\times$ frequency) was used, as all measures were taken only from the FCR muscle. For Experiment III (TMS and Hreflex), the analysis was performed using a two-way repeated measures ANOVA (factors: interval of time $\times$ muscle) while the isokinetic data evaluated by means of Student's paired $t$ test. The level of significance $(\alpha)$ was set at $5 \%$. The statistical analysis was performed using $\mathrm{R}$, version 3.1. The results are presented in terms of means and standard deviations.

\section{Results}

3.1. Experiment I. Figure 3 depicts the results obtained for normalized $\mathrm{MEP}_{\mathrm{P}-\mathrm{P}}$ and FCR H-reflex $\mathrm{P}_{\mathrm{P}}$ values, respectively, immediately after $\left(0^{\prime}\right)$ SES and up to $5^{\prime}$ later for the four frequencies of SES applied during $5^{\prime}$ and for the three muscles (FCR, ECR, and APB). The results obtained after SES set at all the investigated frequencies did not reveal any significant difference among frequencies $(P>0.155)$ and intervals of time $(P>0.087)$ in $\mathrm{MEP}_{\mathrm{P}-\mathrm{P}}$ data as compared to the baseline for all the muscles (Figures 3(a), 3(b), and 3(c)).

Concerning the normalized FCR H-reflex ${ }_{\mathrm{P}-\mathrm{P}}$ values (Figure 3(d)), it also did not show any significant difference among frequencies $(P=0.469)$ and intervals of time $(P=$ $0.177)$ from the baseline.

3.2. Experiment II. Figure 4 depicts the results obtained for normalized $\mathrm{MEP}_{\mathrm{P}-\mathrm{P}}$ and FCR H-reflex $\mathrm{P}_{\mathrm{P}-\mathrm{P}}$ values, respectively, immediately after $\left(0^{\prime}\right)$ SES and up to $5^{\prime}$ and $10^{\prime}$ later for the four frequencies of SES applied during $30^{\prime}$ and for the three muscles (FCR, ECR, and APB). The results obtained after SES set at all the investigated frequencies did not reveal any significant difference among frequencies for FCR $(P=$ $0.443)$ and $\mathrm{APB}(P=0.524)$ muscles. Although there was a significant difference among frequencies for ECR $(P=$ 0.006), they were not statistically different from baseline $(P>$ 0.05). Similarly to Experiment I, there was also no significant difference among intervals of time $(P>0.235)$ in $\mathrm{MEP}_{\mathrm{P}-\mathrm{P}}$ data from the baseline for all the muscles (Figures 4(a), 4(b), and $4(\mathrm{c})$ ).

Our results did not also show any significant difference among frequencies $(P=0.638)$, intervals of time $(P=$ $0.563)$, and interaction of interval of time $\times$ frequency $(P=$ 0.112 ) concerning normalized FCR $\mathrm{H}$-reflex ${ }_{\mathrm{P}-\mathrm{P}}$ values from the baseline.

3.3. Experiment III. Figures 5 and 6 depict the results obtained for the normalized $\mathrm{MEP}_{\mathrm{P}-\mathrm{P}}$ values and latency, respectively, for SES set at $3 \mathrm{~Hz}$ and during $30^{\prime}$. There were no significant differences among intervals of time in normalized $\mathrm{MEP}_{\mathrm{P}-\mathrm{P}}$ relative values from the baseline for all the three muscles, that is, the FCR $(P=0.092), \operatorname{FCRc}(P=0.172)$, ECR $(P=0.814)$, and $\operatorname{APB}(P=0.864)$. Latency measures also did not show any significant difference $(P>0.150)$ concerning baseline values.

The resistance to passive extension (Figure $7(\mathrm{a}) ; P=$ 0.094) and flexion (Figure 7(b); $P=0.774$ ) movements of the wrist joint, evaluated by means of the isokinetic system, also did not show any significant difference for the comparison of measurements collected immediately after $\left(0^{\prime}\right)$ (Post) SES and the baseline (Pre).

\section{Discussion}

It has been proposed that the use of SES in the clinical field can provide improvements similar to those obtained with intensive training [40]. For instance, Conforto et al. [41] observed an increase in the force level of pinch movements in stroke patients after two hours of SES. Dos Santos-Fontes et al. [9] also suggested that SES might lead to long-lasting improvements of paretic arm performance in chronic stroke 


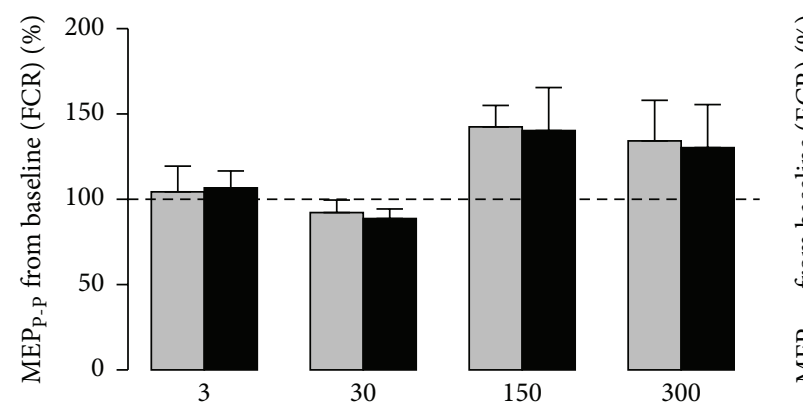

$(\mathrm{Hz})$

(a)

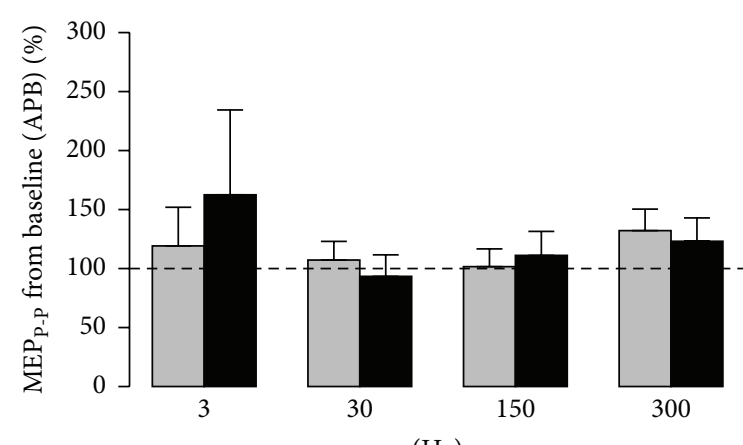

$(\mathrm{Hz})$

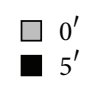

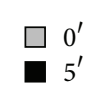

(c)

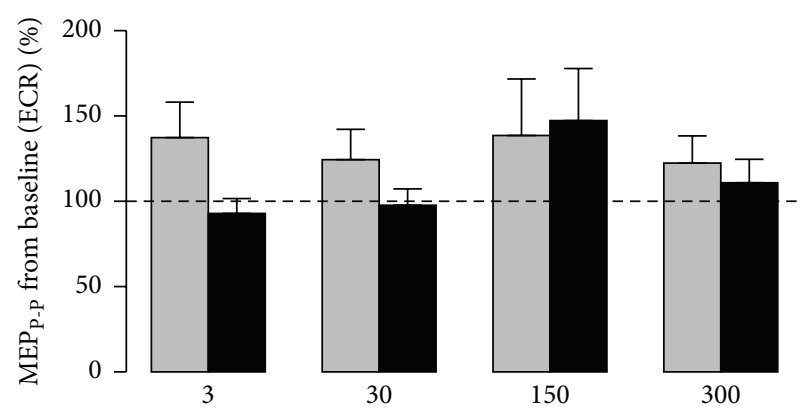

$(\mathrm{Hz})$

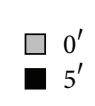

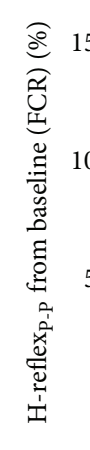

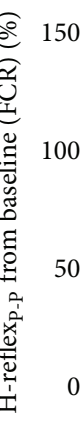

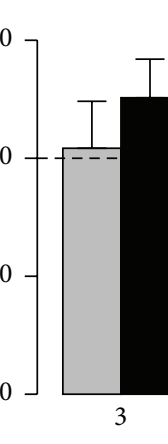

$\square 0^{\prime}$
$\square 5^{\prime}$ (b)

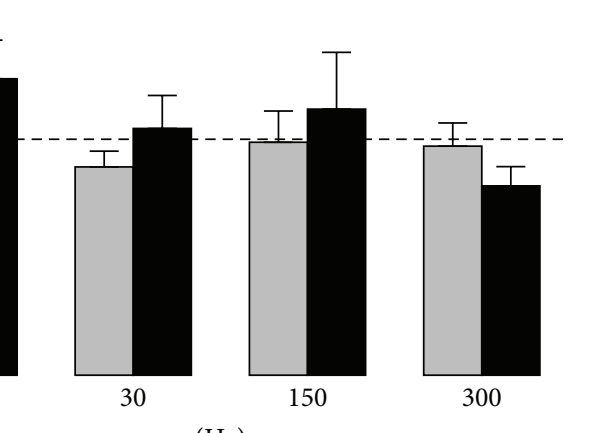

(Hz)

(d)

Figure 3: Normalized $\mathrm{MEP}_{\mathrm{P}-\mathrm{P}}$ values collected immediately after $\left(0^{\prime}\right)$ SES and up to $5^{\prime}$ later at the four frequencies $(3,30,150$, and $300 \mathrm{~Hz})$ for the flexor (FCR) (a) and extensor (ECR) (b) carpi radialis and the abductor pollicis brevis (APB) (c). (d) depicts the results obtained for

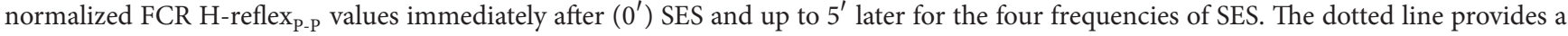
reference from the baseline (before SES) and relative deviations of the results obtained after SES.

patients. Furthermore, SES has been proposed as an alternative approach in minimizing spasticity [6, 7, 42], although there is also no clarity concerning its underlying mechanisms. Hence, despite the above-mentioned examples concerning the positive effects of SES in a clinical setting, there is still no consensus regarding how some of the parameters used in SES (e.g., application time, frequency, intensity, waveform, and pulse width) are taken into account by the central nervous system (CNS) [14, 43]. Therefore, we decided to evaluate the effect of different frequencies of SES in the spinal and corticospinal excitability of healthy volunteers. In addition, we also performed a pilot study to evaluate the effect of SES applied for $30^{\prime}$, in line with clinical practice, and chose a frequency of $3 \mathrm{~Hz}$ applied over the spastic forearm flexor muscles of five stroke patients by means of TMS and passive wrist movement assessment.

Nevertheless, what does the literature tell us about different frequencies of SES in the corticospinal modulation and spasticity? Excitatory as well as inhibitory effects in M1 were shown to be maintained from minutes to hours after SES therapy $[4,13,37,44,45]$. Even though some authors have suggested that an increase in the stimulation frequency might lead preferentially to an increase in M1 excitability $[13,22,38,46,47]$, others reported an opposite effect at the spinal level [48]. We hypothesized that an increase in frequency would allow the ionic current to flow more deeply over the full forearm extent and around the median nerve, which innervates the skin of the palmar side of the thumb, the index, the middle finger, and the APB muscle [49]. As a result, we expected to induce changes in corticospinal excitability of the FCR and APB muscles. However, we also considered the hypothesis of observing some effect in the ECR muscle given that type II afferent fibers (nonadapting sensory fibers) in muscles are able to facilitate or inhibit antagonist muscles [50], although Pierrot-Deseilligny and Burke [36] state that the effect of this interaction on the upper limb is not well understood.

Nevertheless, in the present study, both short $\left(5^{\prime}\right)$ and long $\left(30^{\prime}\right)$ durations of SES applied at different frequencies did not lead to changes in spinal and corticospinal excitability of the muscle under stimulation nor at the muscles that share any kinesiologic property with the stimulated one. 


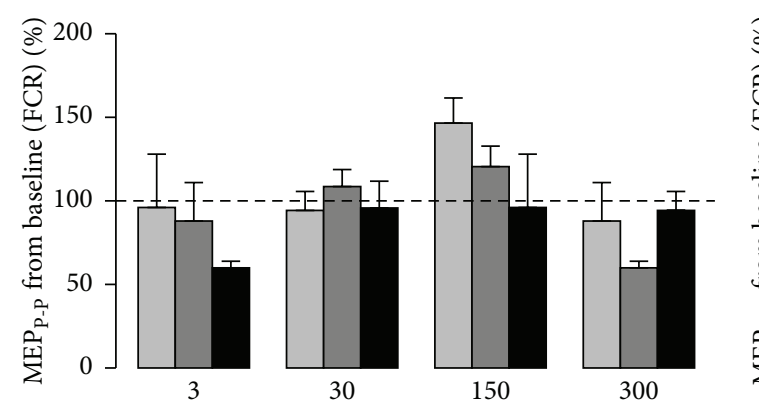

$(\mathrm{Hz})$
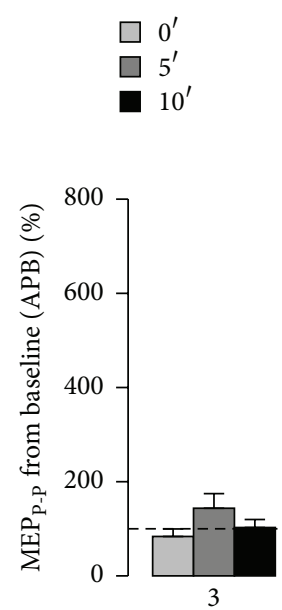

(a)

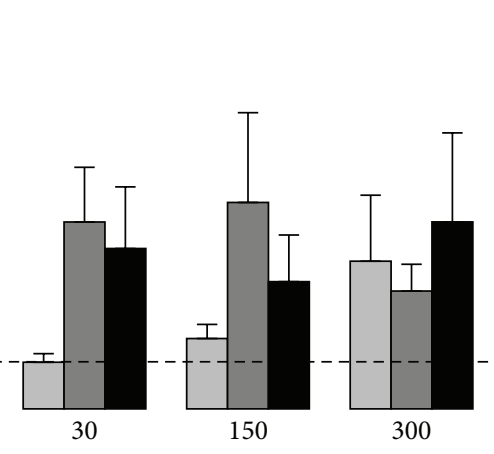

$(\mathrm{Hz})$

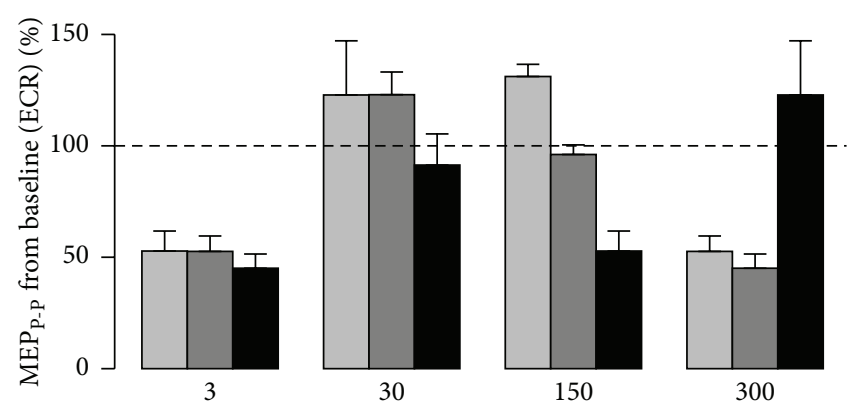

$(\mathrm{Hz})$ $\square 0^{\prime}$
$\square 5^{\prime}$
$\square 10^{\prime}$ $\square 0^{\prime}$
$\square 5^{\prime}$
$\square 10^{\prime}$

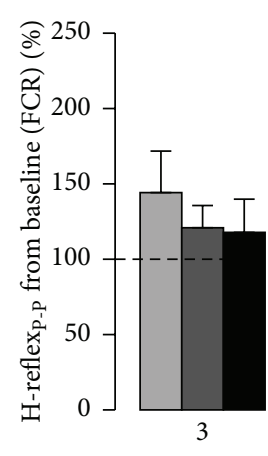

$\square 0^{\prime}$
$\square 5^{\prime}$ (b)

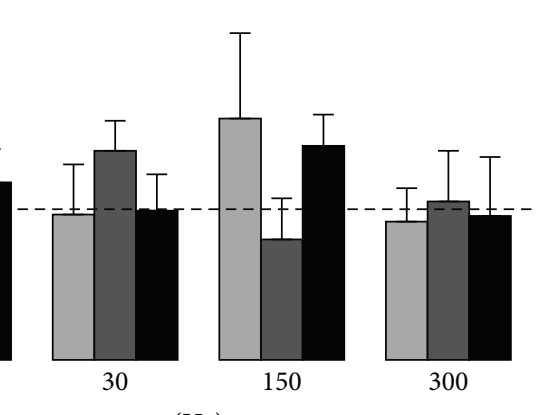

(Hz)

(c)

(d)

FIGURE 4: Normalized $\mathrm{MEP}_{\mathrm{P}-\mathrm{P}}$ values collected immediately after $\left(0^{\prime}\right)$ SES and up to $5^{\prime}$ and $10^{\prime}$ later at the four frequencies $(3,30$, 150, and $300 \mathrm{~Hz}$ ) and for the flexor (FCR) (a) and extensor (ECR) (b) carpi radialis and the abductor pollicis brevis (APB) (c). (d) depicts the results obtained for normalized FCR H-reflex $x_{\text {-P }}$ values immediately after $\left(0^{\prime}\right)$ SES and up to $5^{\prime}$ and $10^{\prime}$ later for the four frequencies of SES. The dotted line provides a reference from the baseline (before SES) and relative deviations of the results obtained after SES.

Despite the discouraging results, some issues in addition to the frequency of stimulation must be taken in account and they are discussed as follows.

4.1. Pulse Width. We used a longer pulse width $(500 \mu \mathrm{s})$ than have other authors (100 to $300 \mu \mathrm{s})[2,6,22]$, which are more selective [26]. We decided on this pulse width due to the need of recruiting a wide range of diameters and modalities of sensory afferents fibers. As our main aim was to evaluate the effect of different frequencies of SES, an increase in the selectivity of recruitment could mask a possible source of a corticospinal excitability modulation derived from this parameter only.

Similar negative and divergent results to ours have also been reported in the literature. For instance, Tinazzi et al. [2] observed an increase and a decrease in the corticospinal excitability of ECR and FCR, respectively, after applying SES at $150 \mathrm{~Hz}$ over the FCR muscle for $30^{\prime}$. On the other hand, Fernandez-del-Olmo et al. [49] performed a similar protocol and did not observe any facilitation or inhibition of both muscles. Curiously, both studies used a narrower pulse $(100 \mu \mathrm{s})$, which is expected to be more selective for larger diameter fibers [16].

A shorter pulse width is expected to achieve higher selectivity in discriminating between somatosensory, motor, and pain sensory nerves. A pulse width of $500 \mu$ s may result in a greater summation of responses from receptors distributed close to the site of SES, which will be integrated and processed at different levels of the CNS and likely transmitted to M1 as an "averaged" signal. Thus, as a first hypothesis to explain the lack of SES modulation we suggest that this averaged input might not be able to induce any spinal or corticospinal modulation.

4.2. The Intensity of SES Stimulation. Another important issue concerns the intensity of the stimulation. Some studies report divergent effects of SES set at different intensity levels in corticospinal excitability but also including paired associated stimulation (PAS) protocols. In this context, Pitcher et al. [22] applied electrical stimulation above the MT and 


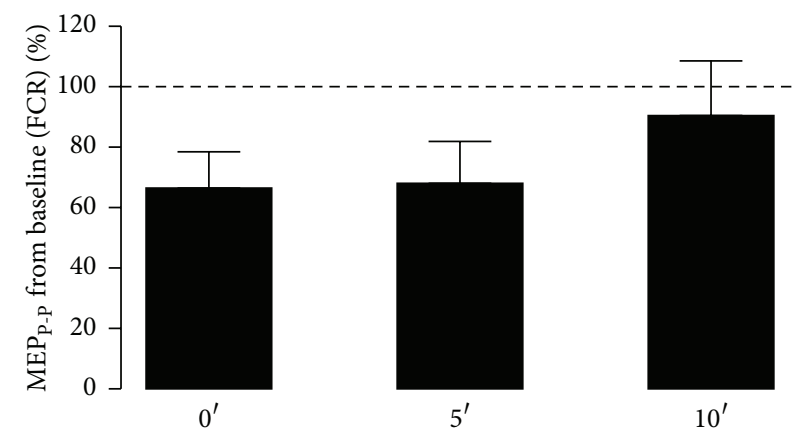

(a)

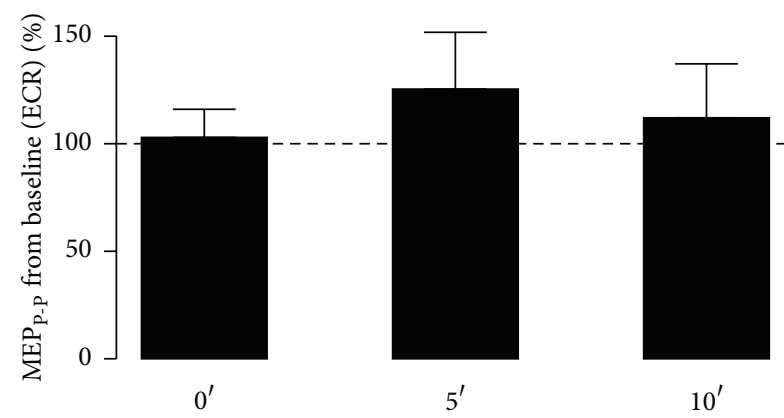

(c)

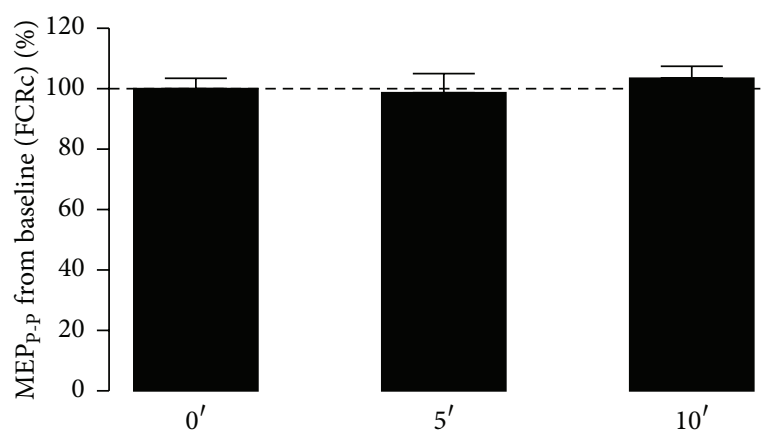

(b)

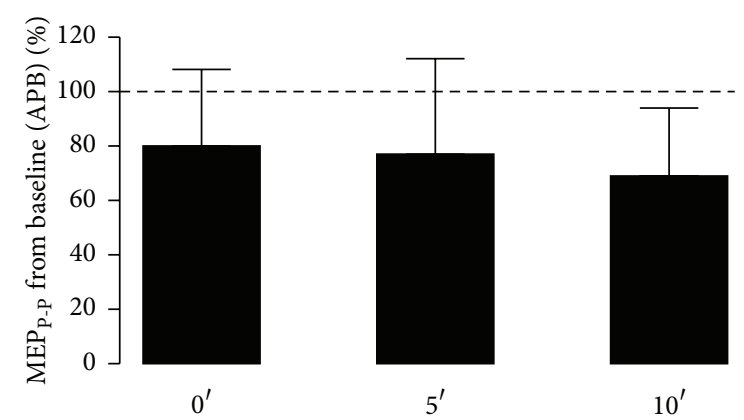

(d)

FIGURE 5: Normalized $\mathrm{MEP}_{\mathrm{P}-\mathrm{P}}$ values collected immediately after $\left(0^{\prime}\right)$ SES and up to $5^{\prime}$ and $10^{\prime}$ later at $3 \mathrm{~Hz}$ for the ipsi (FCR (a)) and contralateral (FCRc (b)) flexor carpi radialis, the extensor carpi radialis (ECR), (c) and the abductor pollicis brevis (APB) (d). The dotted line provides a reference from the baseline (before SES) and relative deviations of the results obtained after SES.

set at $3 \mathrm{~Hz}$ over the first dorsal interosseous (FDI) muscle during $30^{\prime}$ while pulses of TMS were synchronized over the FDI hot-spot in a PAS protocol. They observed a decrease in $\mathrm{MEP}_{\mathrm{P}-\mathrm{P}}$ for approximately $40-50^{\prime}$, suggesting that peripheral electrical stimulation at such low frequency mediates the recruitment of neural circuits that induce long-term depression (LTD). Alternatively, Aimonetti and Nielsen [51] showed that applying a conditioning electrical stimulus just below the MT over the median nerve, which supplies the FCR, produced a facilitation of the ECR for a very short term. In contrast, Bertolasi et al. [52] also showed that applying a conditioning electrical stimulus just above the MT over the median nerve produced an ECR inhibition. Veldman et al. [14] considered that the corticospinal excitability level appears to be modulated by a fine-tuning of SES intensity, which can vary from the perceptual to the motor threshold and be explained by the wide range and directions of neuronal responses obtained from the MEPs in TMS experiments. Moreover, their findings suggest that a stimulation intensity set at the perceptual threshold would not be capable of inducing any modulation in the corticospinal excitability. Based on these remarks and on the methodological approach adopted in the present study to tune the SES intensity (see details above in Section 2), as a second hypothesis we conjecture that, being provided at or very near the perceptual threshold for most of the volunteers, SES did not induce any measurable physiological effect for all the tested muscles, frequencies, and intervals of time.
4.3. The Maintenance of SES Intensity. Another important aspect concerns the maintenance of the stimulation intensity. Different authors adjust the intensity of SES during their experiments to avoid habituation $[3,41,53,54]$. Unlike most of authors, we decided to maintain the same stimulation intensity to avoid a bias in the evaluation of corticospinal modulation after SES. Moreover, we evaluated two different application times of SES: a very short $\left(5^{\prime}\right)$ and a long $\left(30^{\prime}\right)$ one. Therefore, habituation mechanisms must be taken into account even in the SES protocol of short duration. In line with this third hypothesis, the works of Dobkin [55] and Dimitrijević et al. [56] supported the idea that a regular and constant pattern of SES can lead either to habituation/accommodation very quickly or to a failure in producing any change in M1 excitability, although this process does not seem to be rigid. Thus, we suggest as a third hypothesis that a habituation effect induced by the maintenance of the stimulation intensity could be an additional variable of not inducing any spinal or corticospinal modulation from SES in the present study.

4.4. The H-Reflexes ${ }_{P-P}$ Evaluation. Even though we have faced methodological constraints to record the H-reflex from some healthy volunteers, SES seemed to fail to induce changes in the excitability of such measurement in FCR in Experiments I and II. Despite the fact that the H-reflex is generally considered a monosynaptic response, it may be also modulated 


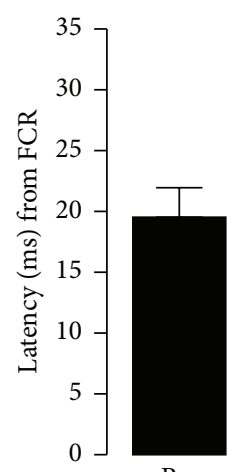

re

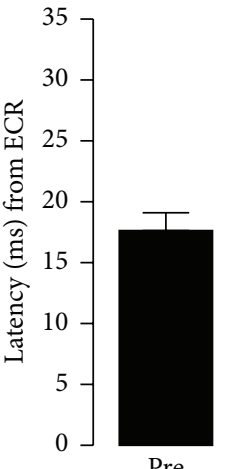

Pre

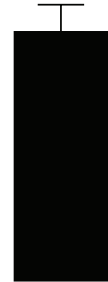

$0^{\prime}$

(a)

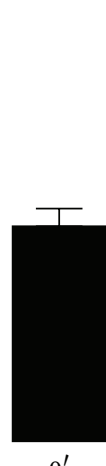

(c)

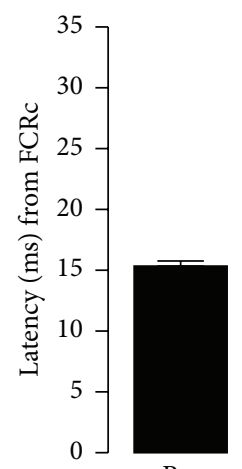

Pre

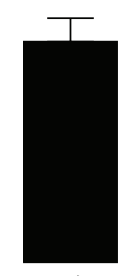

$5^{\prime}$

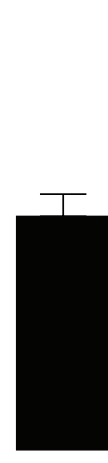

$10^{\prime}$

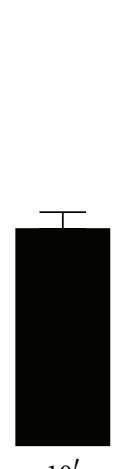

$10^{\prime}$

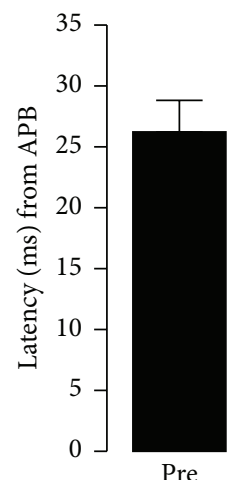

Pre

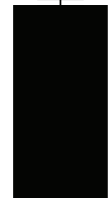

$0^{\prime}$

(b)

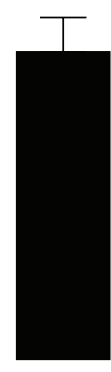

$0^{\prime}$

(d)

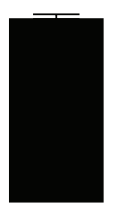

$5^{\prime}$

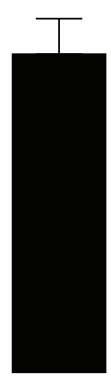

$5^{\prime}$

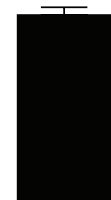

$10^{\prime}$

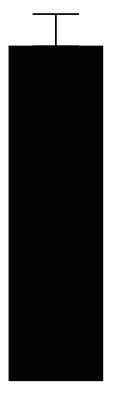

$10^{\prime}$

FIgURE 6: Latency (ms) collected before (Pre) and immediately after $\left(0^{\prime}\right)$ SES and up to $5^{\prime}$ and $10^{\prime}$ later at $3 \mathrm{~Hz}$ for the ipsi (FCR (a)) and contralateral (FCRc-nonaffected side (b)) flexor carpi radialis, the extensor carpi radialis (ECR (c)), and the abductor pollicis brevis (APB) (d).

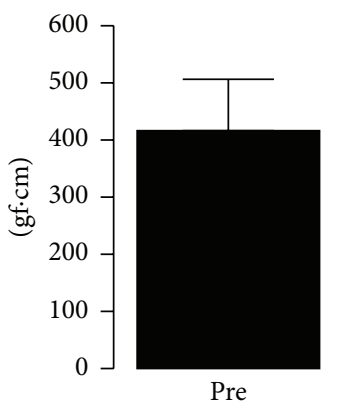

(a)

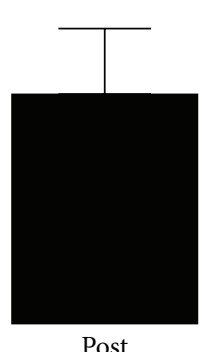

Post

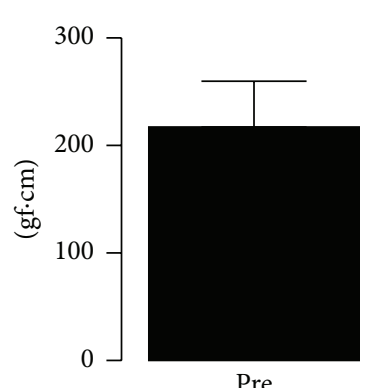

(b)

Figure 7: The torque (gf.cm) values from the resistance to the passive extension ((a) $P=0.094$ ) and flexion ((b) $P=0.774)$ movements of the wrist joint collected before (Pre) and immediately after $\left(0^{\prime}\right)$ (Post) SES for the five stroke patients diagnosed with spasticity.

by other inputs which converge to common interneurons and that may receive inputs from spinal and supraspinal sources $[7,15]$. Therefore, SES seems to stimulate differently specific receptors which might cancel themselves reciprocally and produce a mixture of excitation and inhibition [7], which was previously assumed as one of our hypotheses of not observing any significant difference in corticospinal excitability.

Departing from the herein shown lack of SES effect upon the FCR H-reflex, some studies [57] have shown that functional electrical stimulation (FES), which allows recruiting Ia muscle spindle sensory neurons, is able to induce modulation of the H-reflex in neurological patients and healthy subjects as well. Thus, it may be suggested that Ia afferents, not likely recruited under the SES protocol adopted in this study, could be able to evoke a FCR H-reflex modulation. Hence, the intensity of stimulation might also be a "key-point" in the modulation of spinal reflexes.

4.5. Stroke Spastic Patients. The purpose of this preliminary study was to evaluate for the first time, to our knowledge, the effects of SES set at a low frequency $(3 \mathrm{~Hz})$ over the 
spastic forearm flexor muscles at the corticospinal level in chronic stroke patients. Moreover, we intended to evaluate the carryover effects of SES in the passive mechanical resistance of the impaired wrist joint. Although we did not observe any significant spinal and corticospinal modulation in Experiments I and II, we firstly hypothesized that a decrease in the corticospinal response provided by SES at a low frequency $(3 \mathrm{~Hz})$ [22] would be capable of contributing to decreasing temporarily such muscle overactivity. However, despite the negative results, different authors have provided some interesting arguments and results that preliminarily reinforce our previous hypothesis. As already cited, Pitcher et al. [22] observed that peripheral electrical stimulation at a low frequency results in a decrease in corticospinal excitability, although the hypotheses concerning the likely mechanisms under the effects of this electrical stimulation pattern in spasticity are still lacking. Notwithstanding, Liepert et al. [58] suggested that the intracortical inhibition might be reduced in stroke patients, due to a decreased GABAergic (inhibitory) and/or an increased glutamatergic (excitatory) activity, respectively. The unbalance of those neurotransmitters might contribute to the manifestation of spasticity of supraspinal origin although its physiopathology is still under investigation [59]. Likewise, long-term $\left(>30^{\prime}\right)$ SES at low frequencies might be able to conduct to an increase in the recruitment of GABAergic circuitries and conduct to a depression in corticospinal excitability. Pitcher et al. [22] also support that the modulation of those neural circuitries may be frequency-dependent and might be optimized by $3 \mathrm{~Hz}$ stimulation. Sonde et al. [60] also investigated SES set at a low frequency $(1.7 \mathrm{~Hz})$ in the treatment of spasticity in individuals with stroke and despite the improvements in the motor pattern, they did not also observe any significant decrease in spasticity, as evaluated by means of the Ashworth scale.

Even though the MEPs and wrist torque data did not reach statistically significant levels, the evaluation of the mechanical resistance by means of an isokinetic system, that is, a more accurate and sensible approach, four out of six patients presented relative decreases (5.5 to $14.3 \%$ ) in passive wrist torque (flexion and extension), which might be seen as clinically significant. It is important to highlight that the Ashworth scale does not provide sensitivity to minimal variations on the level of spasticity.

A hyperexcitability of H-reflex has been considered as an index of spasticity $[48,61]$. Therefore, the lack of change in $\mathrm{H}$ reflex measurements does not allow implying spinal instead of corticospinal excitability as the likely portion of the CNS suitable to SES effects in stroke patients with spasticity.

In summary, as we expected to observe a covariation between the MEP behavior with a decrease in resistance to the passive extension movement of the wrist joint, we may also assume that a low frequency of SES set at $3 \mathrm{~Hz}$ and the perceptual threshold might be unable to induce any neuromodulation in these patients.

\section{Conclusion}

Based on the work of Ward [16], we proposed that an increase in the frequency of SES stimulation would allow the ionic current to flow more deeply and so a larger pool of somatosensory receptors from different tissues adjacent to the SES would be recruited. However, even though we must recognize small participant size samples in Experiments II and III, the results provided by our experiments suggest that none of the investigated frequencies $(3,30,150$, and $300 \mathrm{~Hz})$ of SES along with all the other chosen parameters seem to be able to operate as a key in switching modulatory effects in the CNS of healthy volunteers and stroke patients with spasticity.

\section{Conflict of Interests}

The authors declare that there is no conflict of interests.

\section{Acknowledgments}

This work was funded by Coordenação de Aperfeiçoamento de Pessoal de Nível Superior (CAPES), Conselho Nacional de Desenvolvimento científico e Tecnológico (CNPq), and Fundação de Amparo à Pesquisa do Estado do Rio de Janeiro (FAPERJ). This research has also been conducted as part of the activities of FAPESP Research, Dissemination and Innovation Center for Neuromathematics (Grant 2013/07699-0, Fundação de Amparo à Pesquisa do Estado de São Paulo (FAPESP)). Sandro Sperandei is the recipient of a postdoctoral scholarship from FAPERJ and CAPES.

\section{References}

[1] M. A. Perez, E. C. Field-Fote, and M. K. Floeter, "Patterned sensory stimulation induces plasticity in reciprocal Ia inhibition in humans," The Journal of Neuroscience, vol. 23, no. 6, pp. 20142018, 2003.

[2] M. Tinazzi, S. Zarattini, M. Valeriani et al., "Long-lasting modulation of human motor cortex following prolonged transcutaneous electrical nerve stimulation (TENS) of forearm muscles: evidence of reciprocal inhibition and facilitation," Experimental Brain Research, vol. 161, no. 4, pp. 457-464, 2005.

[3] A. B. Conforto, L. G. Cohen, R. L. D. Santos, M. Scaff, and S. K. N. Marie, "Effects of somatosensory stimulation on motor function in chronic cortico-subcortical strokes," Journal of Neurology, vol. 254, no. 3, pp. 333-339, 2007.

[4] A. Kaelin-Lang, A. R. Luft, L. Sawaki, A. H. Burstein, Y. H. Sohn, and L. G. Cohen, "Modulation of human corticomotor excitability by somatosensory input," The Journal of Physiology, vol. 540, no. 2, pp. 623-633, 2002.

[5] V. Gritsenko and A. Prochazka, "A functional electric stimulation-assisted exercise therapy system for hemiplegic hand function," Archives of Physical Medicine and Rehabilitation, vol. 85, no. 6, pp. 881-885, 2004.

[6] A. van der Salm, P. H. Veltink, M. J. IJzerman, K. C. GroothuisOudshoorn, A. V. Nene, and H. J. Hermens, "Comparison of electric stimulation methods for reduction of triceps surae spasticity in spinal cord injury," Archives of Physical Medicine and Rehabilitation, vol. 87, no. 2, pp. 222-228, 2006.

[7] A. Klaiput and W. Kitisomprayoonkul, "Increased pinch strength in acute and subacute stroke patients after simultaneous median and ulnar sensory stimulation," Neurorehabilitation and Neural Repair, vol. 23, no. 4, pp. 351-356, 2009. 
[8] D. J. Werring, "Improving hand motor control after stroke," Journal of Neurology, Neurosurgery \& Psychiatry, vol. 80, no. 6, p. 586, 2009.

[9] R. L. Dos Santos-Fontes, K. N. Ferreiro De Andrade, A. Sterr, and A. B. Conforto, "Home-based nerve stimulation to enhance effects of motor training in patients in the chronic phase after stroke: a proof-of-principle study," Neurorehabilitation and Neural Repair, vol. 27, no. 6, pp. 483-490, 2013.

[10] B. P. Ho Chung and B. K. K. Cheng, "Immediate effect of transcutaneous electrical nerve stimulation on spasticity in patients with spinal cord injury," Clinical Rehabilitation, vol. 24, no. 3, pp. 202-210, 2010.

[11] C. K. Thompson, M. D. Lewek, A. Jayaraman, and T. G. Hornby, "Central excitability contributes to supramaximal volitional contractions in human incomplete spinal cord injury," The Journal of Physiology, vol. 589, no. 15, pp. 3739-3752, 2011.

[12] Y. Laufer and M. Elboim-Gabyzon, "Does sensory transcutaneous electrical stimulation enhance motor recovery following a stroke? A systematic review," Neurorehabilitation and Neural Repair, vol. 25, no. 9, pp. 799-809, 2011.

[13] L. S. Chipchase, S. M. Schabrun, and P. W. Hodges, "Corticospinal excitability is dependent on the parameters of peripheral electric stimulation: a preliminary study," Archives of Physical Medicine and Rehabilitation, vol. 92, no. 9, pp. 14231430, 2011.

[14] M. P. Veldman, N. A. Maffiuletti, M. Hallett, I. Zijdewind, and T. Hortobágyi, "Direct and crossed effects of somatosensory stimulation on neuronal excitability and motor performance in humans," Neuroscience \& Biobehavioral Reviews, vol. 47, pp. $22-$ 35, 2014.

[15] C. J. McNeil, J. E. Butler, J. L. Taylor, and S. C. Gandevia, “Testing the excitability of human motoneurones," Frontiers in Human Neuroscience, vol. 7, article 152, 2013.

[16] A. R. Ward, "Electrical stimulation using kilohertz-frequency alternating current," Physical Therapy, vol. 89, no. 2, pp. 181-190, 2009.

[17] R. C. Oldfield, "The assessment and analysis of handedness: the Edinburgh inventory," Neuropsychologia, vol. 9, no. 1, pp. 97-113, 1971.

[18] S. Rossi, M. Hallett, P. M. Rossini et al., "Safety, ethical considerations, and application guidelines for the use of transcranial magnetic stimulation in clinical practice and research," Clinical Neurophysiology, vol. 120, no. 12, pp. 2008-2039, 2009.

[19] R. W. Bohannon and M. B. Smith, "Interrater reliability of a modified Ashworth scale of muscle spasticity," Physical Therapy, vol. 67, no. 2, pp. 206-207, 1987.

[20] S. M. D. Brucki, R. Nitrin, P. Caramelli, P. H. F. Bertolucci, and I. H. Okamoto, "Suggestions for utilization of the mini-mental state examination in Brazil," Arquivos de Neuro-Psiquiatria, vol. 61, no. 3-8, pp. 777-781, 2003.

[21] W. W. Campbell, DeJong's The Neurologic Examination, LLW, Riverwoods, Ill, USA, 7th edition, 2012.

[22] J. B. Pitcher, M. C. Ridding, and T. S. Miles, "Frequencydependent, bi-directional plasticity in motor cortex of human adults," Clinical Neurophysiology, vol. 114, no. 7, pp. 1265-1271, 2003.

[23] F. Albert, M. Bergenheim, E. Ribot-Ciscar, and J.-P. Roll, “The Ia afferent feedback of a given movement evokes the illusion of the same movement when returned to the subject via muscle tendon vibration," Experimental Brain Research, vol. 172, no. 2, pp. 163-174, 2006.
[24] R. Fuentes, P. Petersson, W. B. Siesser, M. G. Caron, and M. A. L. Nicolelis, "Spinal cord stimulation restores locomotion in animal models of Parkinson's disease," Science, vol. 323, no. 5921, pp. 1578-1582, 2009.

[25] J. M. Y. Catunda, Effect of different frequencies of electrical stimulation in the Hoffman reflex and the passive resistance wrist movement in healthy subjects [M.S. thesis], Program of Biomedical Engineering, COPPE, UFRJ, Rio de Janeiro, Brazil, 2009.

[26] R. B. Szlavik and H. de Bruin, "The effect of stimulus current pulse width on nerve fiber size recruitment patterns," Medical Engineering \& Physics, vol. 21, no. 6-7, pp. 507-515, 1999.

[27] J. B. Velloso and M. N. Souza, "A programmable system of functional electrical stimulation (FES)," in Proceedings of the 29th Annual International Conference of IEEE-EMBS, Engineering in Medicine and Biology Society (EMBC '07), pp. 2234-2237, IEEE, Lyon, France, August 2007.

[28] F. Baldissera, G. Bellani, P. Cavallari, and S. Lalli, "Changes in the excitability of the H-reflex in wrist flexors related to the prone or supine position of the forearm in man," Neuroscience Letters, vol. 295, no. 3, pp. 105-108, 2000.

[29] H. J. Hermens, B. Freriks, C. Disselhorst-Klug, and G. Rau, "Development of recommendations for SEMG sensors and sensor placement procedures," Journal of Electromyography and Kinesiology, vol. 10, no. 5, pp. 361-374, 2000.

[30] A. B. Conforto, S. K. N. Marie, L. G. Cohen, and M. Scaff, "Estimulação magnética transcraniana," Arquivos de NeuroPsiquiatria, vol. 61, no. 1, pp. 146-152, 2003.

[31] M. Kobayashi and A. Pascual-Leone, "Transcranial magnetic stimulation in neurology," The Lancet Neurology, vol. 2, no. 3, pp. 145-156, 2003.

[32] C. Mercier, K. T. Reilly, C. D. Vargas, A. Aballea, and A. Sirigu, "Mapping phantom movement representations in the motor cortex of amputees," Brain, vol. 129, no. 8, pp. 2202-2210, 2006.

[33] R. S. A. Brinkworth, M. Tuncer, K. J. Tucker, S. Jaberzadeh, and K. S. Türker, "Standardization of H-reflex analyses," Journal of Neuroscience Methods, vol. 162, no. 1-2, pp. 1-7, 2007.

[34] S. Malhotra, A. D. Pandyan, C. R. Day, P. W. Jones, and H. Hermens, "Spasticity, an impairment that is poorly defined and poorly measured," Clinical Rehabilitation, vol. 23, no. 7, pp. 651658, 2009.

[35] M. Hallett, "Transcranial magnetic stimulation and the human brain," Nature, vol. 406, no. 6792, pp. 147-150, 2000.

[36] E. Pierrot-Deseilligny and D. Burke, The Circuitry of the Spinal Cord: Its Role in Motor Control and Movement, Cambridge University Press, New York, NY, USA, 2005.

[37] M. C. Ridding and J. L. Taylor, "Mechanisms of motor-evoked potential facilitation following prolonged dual peripheral and central stimulation in humans," Journal of Physiology, vol. 537, part 2, pp. 623-631, 2001.

[38] C. S. Charlton, M. C. Ridding, P. D. Thompson, and T. S. Miles, "Prolonged peripheral nerve stimulation induces persistent changes in excitability of human motor cortex," Journal of the Neurological Sciences, vol. 208, no. 1-2, pp. 79-85, 2003.

[39] F. D. Roy and M. A. Gorassini, "Peripheral sensory activation of cortical circuits in the leg motor cortex of man," Journal of Physiology, vol. 586, no. 17, pp. 4091-4105, 2008.

[40] T. Kalisch, M. Tegenthoff, and H. R. Dinse, "Sensory stimulation therapy," Frontiers in Neuroscience, vol. 3, pp. 96-97, 2009.

[41] A. B. Conforto, A. Kaelin-Lang, and L. G. Cohen, "Increase in hand muscle strength of stroke patients after somatosensory 
stimulation," Annals of Neurology, vol. 51, no. 1, pp. 122-125, 2002.

[42] J. P. A. Dewald, J. D. Given, and W. Z. Rymer, "Long-lasting reductions of spasticity induced by skin electrical stimulation," IEEE Transactions on Rehabilitation Engineering, vol. 4, no. 4, pp. 231-242, 1996.

[43] J. H. Burridge and M. Ladouceur, "Clinical and therapeutic applications of neuromuscular stimulation: a review of current use and speculation into future developments," Neuromodulation, vol. 4, no. 4, pp. 147-153, 2001.

[44] M. C. Ridding, D. R. McKay, P. D. Thompson, and T. S. Miles, "Changes in corticomotor representations induced by prolonged peripheral nerve stimulation in humans," Clinical Neurophysiology, vol. 112, no. 8, pp. 1461-1469, 2001.

[45] J. R. de Kroon, M. J. IJzerman, J. Chae, G. J. Lankhorst, and G. Zilvold, "Relation between stimulation characteristics and clinical outcome in studies using electrical stimulation to improve motor control of the upper extremity in stroke," Journal of Rehabilitation Medicine, vol. 37, no. 2, pp. 65-74, 2005.

[46] J. Uy and M. C. Ridding, "Increased cortical excitability induced by transcranial DC and peripheral nerve stimulation," Journal of Neuroscience Methods, vol. 127, no. 2, pp. 193-197, 2003.

[47] S. Khaslavskaia and T. Sinkjaer, "Motor cortex excitability following repetitive electrical stimulation of the common peroneal nerve depends on the voluntary drive," Experimental Brain Research, vol. 162, no. 4, pp. 497-502, 2005.

[48] M. F. Levin and C. W. Y. Hui-Chan, "Relief of hemiparetic spasticity by TENS is associated with improvement in reflex and voluntary motor functions," Electroencephalography and Clinical Neurophysiology, vol. 85, no. 2, pp. 131-142, 1992.

[49] M. Fernandez-del-Olmo, M. Alvarez-Sauco, G. Koch et al., "How repeatable are the physiological effects of TENS?" Clinical Neurophysiology, vol. 119, no. 8, pp. 1834-1839, 2008.

[50] V. J. Wilson and M. Kato, "Excitation of extensor motoneurons by group II afferent fibers in ipsilateral muscle nerves," Journal of Neurophysiology, vol. 28, no. 3, pp. 545-554, 1965.

[51] J.-M. Aimonetti and J. B. Nielsen, "Changes in intracortical excitability induced by stimulation of wrist afferents in man," Journal of Physiology, vol. 534, no. 3, pp. 891-902, 2001.

[52] L. Bertolasi, A. Priori, M. Tinazzi, V. Bertasi, and J. C. Rothwell, "Inhibitory action of forearm flexor muscle afferents on corticospinal outputs to antagonist muscles in humans," The Journal of Physiology, vol. 511, no. 3, pp. 947-956, 1998.

[53] R.-Y. Wang, M.-W. Tsai, and R.-C. Chan, "Effects of surface spinal cord stimulation on spasticity and quantitative assessment of muscle tone in hemiplegic patients," American Journal of Physical Medicine \& Rehabilitation, vol. 77, no. 4, pp. 282-287, 1998.

[54] A. B. Conforto, K. C. Ferreiro, C. Tomasi et al., "Effects of somatosensory stimulation on motor function after subacute stroke," Neurorehabilitation and Neural Repair, vol. 24, no. 3, pp. 263-272, 2010.

[55] B. H. Dobkin, "Do electrically stimulated sensory inputs and movements lead to long-term plasticity and rehabilitation gains?” Current Opinion in Neurology, vol. 16, no. 6, pp. 685691, 2003.

[56] M. R. Dimitrijević, J. Faganel, M. Gregorić, P. W. Nathan, and J. K. Trontelj, "Habituation: effects of regular and stochastic stimulation," Journal of Neurology Neurosurgery and Psychiatry, vol. 35, no. 2, pp. 234-242, 1972.
[57] N. Kawashima, M. R. Popovic, and V. Zivanovic, "Effect of intensive functional electrical stimulation therapy on upperlimb motor recovery after stroke: case study of a patient with chronic stroke," Physiotherapy Canada, vol. 65, no. 1, pp. 20-28, 2013.

[58] J. Liepert, P. Storch, A. Fritsch, and C. Weiller, "Motor cortex disinhibition in acute stroke," Clinical Neurophysiology, vol. 111, no. 4, pp. 671-676, 2000.

[59] D. Burke, J. Wissel, and G. A. Donnan, "Pathophysiology of spasticity in stroke," Neurology, vol. 80, supplement 2, pp. S20S26, 2013.

[60] L. Sonde, C. Gip, S. E. Fernaeus, C. G. Nilsson, and M. Viitanen, "Stimulation with low frequency $(1.7 \mathrm{~Hz})$ transcutaneous electric nerve stimulation (low-tens) increases motor function of the post-stroke paretic arm," Scandinavian Journal of Rehabilitation Medicine, vol. 30, no. 2, pp. 95-99, 1998.

[61] A. H. Bakhtiary and E. Fatemy, "Does electrical stimulation reduce spasticity after stroke? A randomized controlled study," Clinical Rehabilitation, vol. 22, no. 5, pp. 418-425, 2008. 

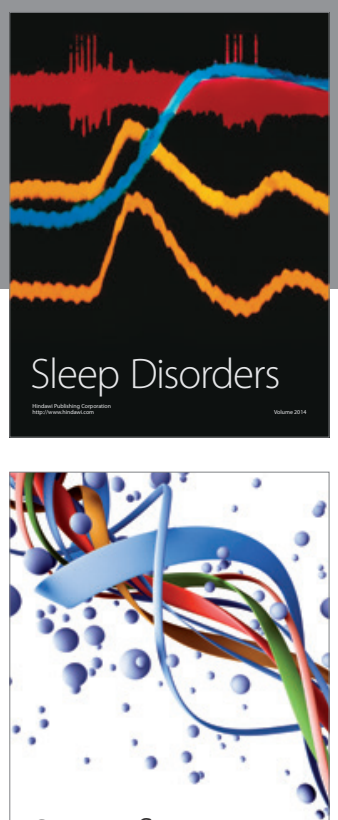

Scientifica
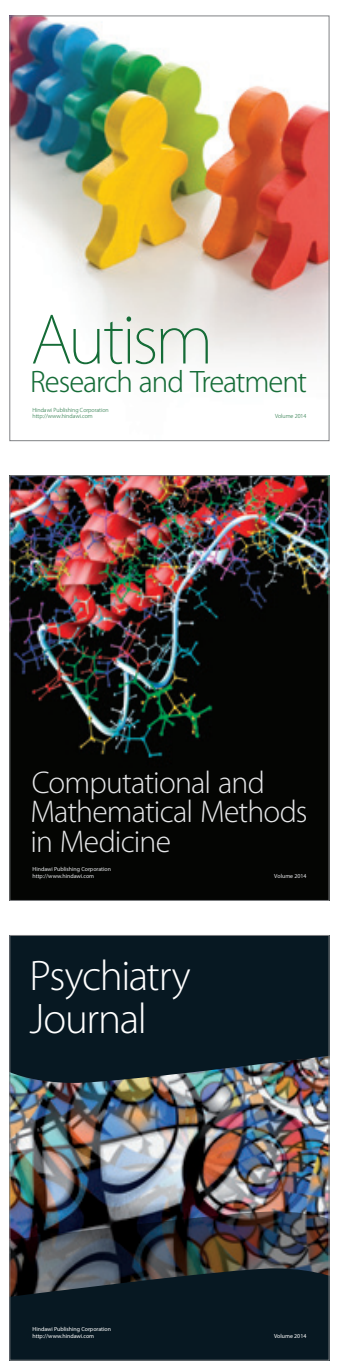
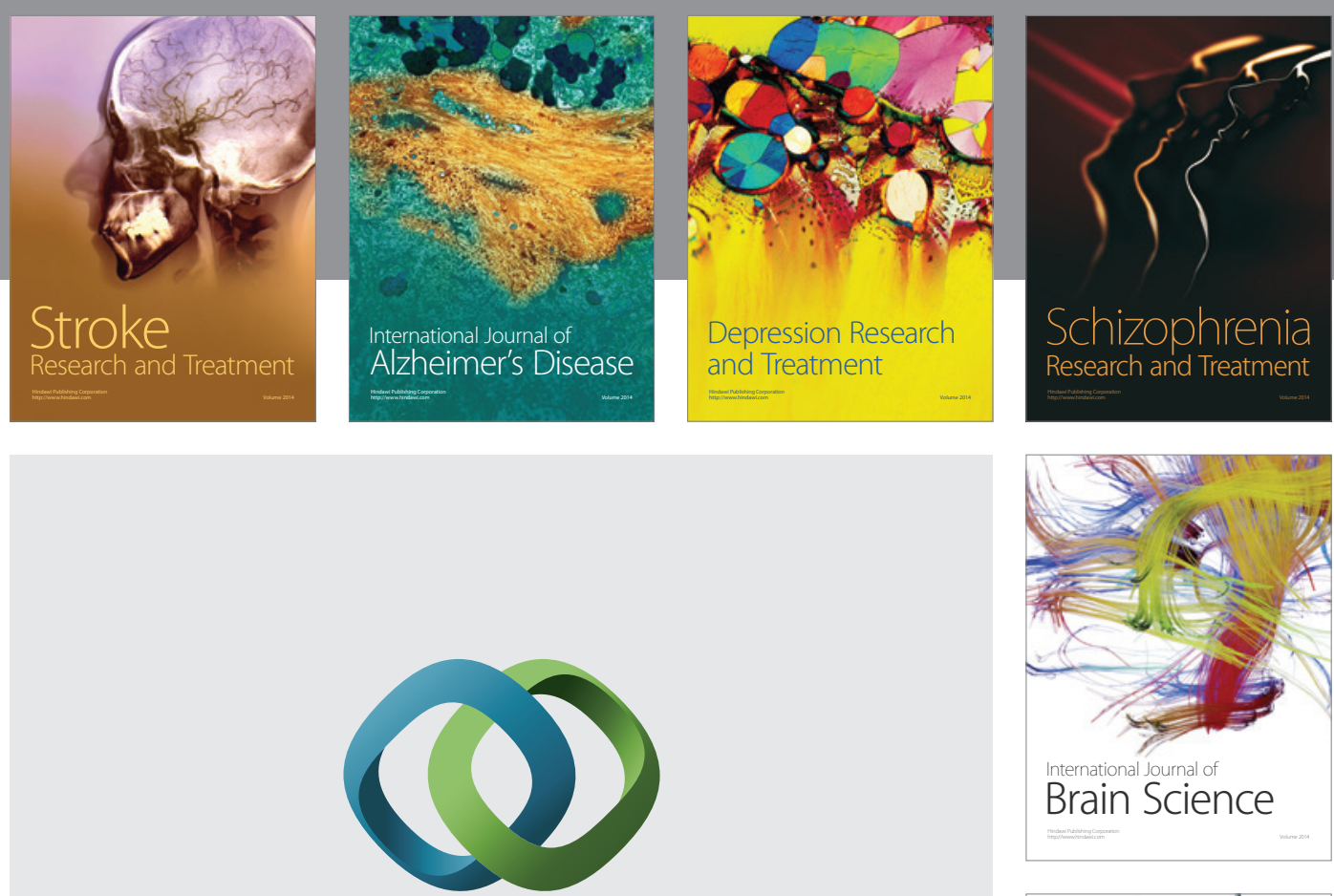

\section{Hindawi}

Submit your manuscripts at

http://www.hindawi.com
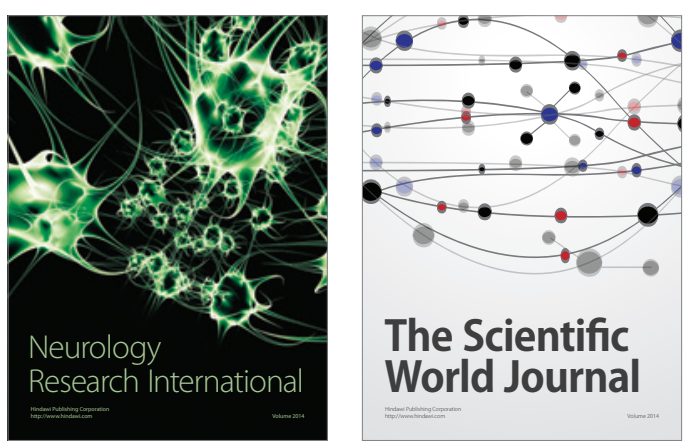

The Scientific World Journal

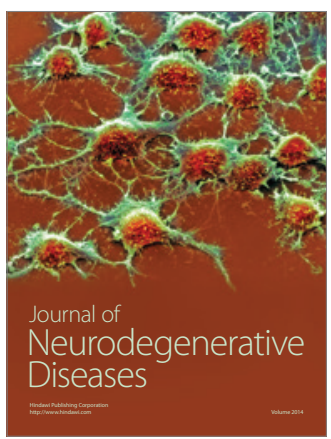

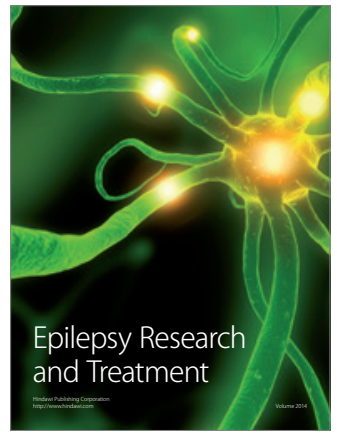

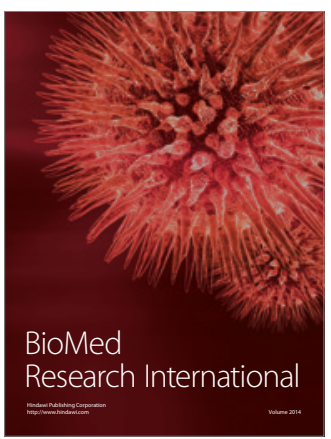

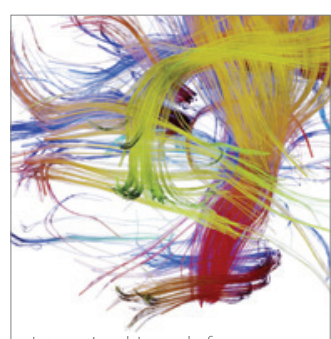

Brain Science

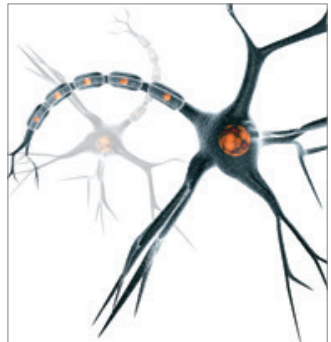

Neural Plasticity
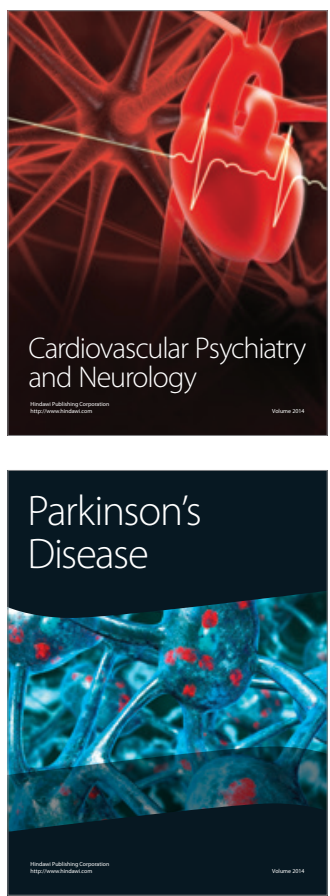